\title{
zonafunces
}

\section{MANCINI, Eduardo y CABALLERO, Mariana (Compiladores) (2020). Maestras argentinas. Entre mandatos y transgresiones. Rosario, Centro Cultural de La Toma Ediciones, Asociación Civil Inconsciente Colectivo, Cooperativa de Pensamiento Margarito Tereré, 721 pp.}

Este libro recupera las múltiples trayectorias profesionales y militantes de maestras argentinas a partir de un recorrido diacrónico, que se inicia con la labor de beatas y monjas en la época colonial, hasta educadoras de nuestra contemporaneidad. La obra, que se divide en dos tomos, es producto de un sustancial esfuerzo colectivo donde se compilan textos biográficos y se comparten experiencias educativas a través de 103 capítulos escritos por 91 autoras/es de diferentes procedencias académicas, pedagógicas e institucionales.

El trabajo de muchas de las docentes aquí reunidas ha permanecido invisibilizado o poco reconocido durante décadas, tanto en el campo educativo como por el discurso historiográfico androcéntrico. Sus aportes han sido fundamentales no sólo para ciertas "renovaciones pedagógicas" y la defensa de los derechos de las infancias, adolescencias y juventudes, sino también para la conquista y la ampliación de los derechos laborales de un colectivo altamente feminizado.

En nuestro país, la feminización dentro del nivel primario se llevó a cabo de forma acelerada a fines del siglo XIX y la primera década del XX. Las investigaciones realizadas por Yannoulas y Morgade durante los años noventa fueron pioneras al introducir la perspectiva de género en la historia de la educación. Estos estudios analizaron de manera crítica las representaciones hegemónicas de la época.

Las mujeres fueron consideradas "educadoras por excelencia", y de este modo la aparición y consolidación de la mano de obra femenina contribuyó a formar un nuevo espacio social, que hizo borrosas las fronteras entre lo público y privado.

Revista Zona Franca- Centro de estudios interdisciplinario sobre las mujeres (CEIM)- Maestría poder y sociedad desde la problemática de género (MG), Rosario, Argentina. ISSN, 2545-6504 http://zonafranca.unr.edu.ar/index.php/ZonaFranca| Número 29 (2021). 
Además, ofrecían algunas ventajas en relación al rol que podían cumplir los maestros, ya que para los políticos y los pedagogos de aquel entonces "las mujeres instruían menos pero educaban más".

Entre mandatos y transgresiones, se ubican los intersticios de figuras que abrieron paso a las prerrogativas impuestas por el heteropatriarcado, que hizo del ejercicio docente una extensión de la maternidad, adjudicándoles dentro y fuera del hogar la formación de las jóvenes generaciones.

La relación directa establecida entre "capacidades educadoras" y "capacidades maternales", justificaron la histórica devaluación de esta profesión. Al mismo tiempo, los discursos imperantes les cercenaron posiciones de poder dentro del propio sistema educativo.

En el recorrido propuesto, las biografías individuales se entrecruzan con la historia socio-política del sistema educativo nacional y su consolidación que tuvo su punto de efervescencia hacia fines del siglo XIX y principios del XX. En este contexto, los agenciamientos estatales que operaron en el imaginario social dominante para formar a "los ciudadanos" que el país supuestamente necesitaba, entraron en conflicto con el accionar de las primeras maestras anarquistas, socialistas y comunistas. Entre ellas se destacaron Gabriella Laperriére, Fenia Chertkoff, Haydée Maciel, Raquel Camaña, Carolina Muzzilli, Pascuala Cueto.

El trabajo completo pone en tensión permanente en los ámbitos educativos formal y no formal las posibilidades de las maestras de romper con los márgenes establecidos por el propio sistema educativo. No obstante, algunas biografiadas, fueron obedientes reproductoras del mandato estatal y homogeneizador del normalismo argentino asumiendo una posición cómoda y disciplinadora, este fue el caso de Ángela Peralta Pino, Luz Méndez y Amanda Arias.

Por el contrario, otras afirmaron su independencia y optaron por rumbos críticos, problematizaron el rol docente, se subsumieron en marcos teóricos

Revista Zona Franca- Centro de estudios interdisciplinario sobre las mujeres (CEIM)- Maestría poder y sociedad desde la problemática de género (MG), Rosario, Argentina. ISSN, 2545-6504 http://zonafranca.unr.edu.ar/index.php/ZonaFranca| Número 29 (2021). 
renovadores. Por ese motivo, buscaron en otras áreas de conocimiento herramientas para potenciar la tarea pedagógica, dentro y fuera de las instituciones educativas.

En el primer tomo, se visibilizan las voces y el accionar de mujeres que pese a los mandatos de género, ampliaron sus horizontes formativos más allá de las escuelas normales. Algunas iniciaron importantes reivindicaciones para acceder al ámbito universitario y defendieron los derechos de las mujeres, como Petrona Eyle, Elvira Rawson, Elvira López y Ernestina López. Otras de manera paralela, también se dedicaron a la escritura, el periodismo y la abogacía. Tales fueron las experiencias de Carlotta Garrido, María Abella, Ada Elflein, Marta Marucco, Alfonsina Storni, Herminia Brumana, Marta Samatán, Emma Barrandéguy.

El trabajo no se centra exclusivamente en biografiadas de los grandes centros urbanos de nuestro país cuya producción de conocimiento es más difundida en los estudios superiores. Así, se rompen los límites espaciales y temporales para acercar a maestras que enseñaron en las montañas, las islas, la ruralidad, contextos de encierros y barrios populares.

En el segundo tomo, adquieren protagonismo aquellas que trabajaron y resistieron a las dictaduras cívicos-militares, militantes de Derechos Humanos, de la diversidad sexual y activistas que estuvieron al frente de las batallas contra el neoliberalismo en nuestro país. Iniciado el siglo XXI llegan biografías de docentes de los pueblos originarios, disidentes del binarismo heterosexual y militantes tradicionalmente marginadas del magisterio. En este sentido, se puede aludir a la participación activa de Stella Maldonado, Marta Maffei, Liliana Scavuzzo, entre otras.

El libro compilado por Mariana Caballero y Eduardo Mancini rescata del polvo de los archivos historias de maestras que bregaron por la inclusión, crearon escuelas populares, ensayaron experiencias de educación no formal, cargaron sobre sus espaldas escuelas rurales o eligieron alfabetizar en villas miserias. Al

Revista Zona Franca- Centro de estudios interdisciplinario sobre las mujeres (CEIM)- Maestría poder y sociedad desde la problemática de género (MG), Rosario, Argentina. ISSN, 2545-6504 http://zonafranca.unr.edu.ar/index.php/ZonaFranca| Número 29 (2021). 
romper con los límites de lo establecido y el mandato heteropatriarcal, muchas de ellas protagonizaron los largos procesos que fueron desde las primeras asociaciones mutuales, hasta la creación en 1973 de unos de los sindicatos más importantes del país, como es la Confederación de Trabajadores/as de la Educación de la República Argentina (CTERA). Fue justamente por la participación gremial y militante que algunas de las biografiadas fueron desaparecidas durante el último golpe cívico militar que se impuso desde 1976 hasta 1983 en Argentina, como Marina Vilte, Nora Larrosa y Graciela Lo Tufo.

Al concluir el segundo tomo, las/los lectoras/es se encuentran con historias de figuras que, lejos de ser consideradas como "la segunda madre", se apropiaron de su condición de trabajadoras de la educación. Por ello, cada biografiada es el eslabón de una larga cadena de luchas y resistencias, dentro y fuera del sistema educativo. En su gran mayoría ampliaron los horizontes del mundo simbólico y resignificaron la tarea docente, principalmente en la educación primaria, aunque también se incluyen otros niveles y modalidades de enseñanza.

Para finalizar, este libro no solamente es un material imprescindible para comprender parte del magisterio local, sino también bibliografía de consulta en las carreras de Nivel Superior y Universitario por su contenido diverso. Y por el intento de desocultar historias desconocidas por el discurso hegemónico de la historia tradicional.

El presente proyecto colectivo, gestado al calor de la pandemia del Covid-19, tiene una aspiración mayor que es la paulatina producción de un audio-libro, cuyos capítulos se pueden escuchar por Internet. En la lectura de los textos participaron los/las autores/as y también otros/as narradores/as que sumaron sus voces a esa iniciativa. El libro compilado por Mancini y Caballero, no contiene una versión definitiva de todas las maestras argentinas de nuestro país, pero sí de muchas y con una mirada amplia, reflexiva y federal. En él se rescatan diversas historias de resistencias, rebeldías y esperanzas pero lejos de pretender una visión definitiva, la

Revista Zona Franca- Centro de estudios interdisciplinario sobre las mujeres (CEIM)- Maestría poder y sociedad desde la problemática de género (MG), Rosario, Argentina. ISSN, 2545-6504 http://zonafranca.unr.edu.ar/index.php/ZonaFranca| Número 29 (2021). 
obra reseñada puede leerse como un eslabón más, dentro de la compleja historia socioeducativa del sistema escolar argentino.

\title{
Bibliografía
}

MORGADE Graciela (1997) (Comp.) Mujeres en la educación. Género y docencia en la Argentina 1870-1930. Miño y Dávila Editores, Buenos Aires.

YAGNNOULAS Silvia (1996) Educar: ¿una profesión de mujeres? La feminización del normalismo y la docencia (1870-1930). Kapeluz, Buenos Aires.

\author{
Raquel María González* \\ Juan Pablo Robledo* *
}

* Universidad Nacional de Rosario (UNR). Contacto: raquelmgonzalez1985@gmail.com

** Universidad Nacional de Rosario (UNR). Contacto: robledojuanpablo@gmail.com

Revista Zona Franca- Centro de estudios interdisciplinario sobre las mujeres (CEIM)- Maestría poder y sociedad desde la problemática de género (MG), Rosario, Argentina. ISSN, 2545-6504 http://zonafranca.unr.edu.ar/index.php/ZonaFrancal Número 29 (2021). 